\title{
Control of Bovine Brucellosis from Persistently Infected Holdings Using RB51 Vaccination with Test-and-Slaughter: A Comparative Case Report from a High Incidence Area in Portugal
}

\author{
M. C. Caetano ${ }^{1}$, F. Afonso ${ }^{1}$, R. Ribeiro ${ }^{2}$, A. P. Fonseca ${ }^{1}$, D. A. Abernethy ${ }^{3}$ and F. Boinas ${ }^{2}$ \\ 1 Direcção Geral de Alimentação e Veterinária, Largo da Academia Nacional de Belas Artes, Lisbon, Portugal \\ 2 Centro de Investigação Interdisciplinar em Sanidade Animal (CIISA), Faculdade de Medicina Veterinária, Universidade de Lisboa, Lisbon, Portugal \\ 3 Department of Veterinary Tropical Diseases, Faculty of Veterinary Science, University of Pretoria, Onderstepoort, South Africa
}

\begin{abstract}
Correspondence:
F. Boinas. Faculdade de Medicina Veterin 'aria, Universidade de Lisboa, Avenida da Universidade T'ecnica de Lisboa, 1300-477 Lisboa, Portugal. Tel.: +351 213652856; Fax: +351 213652887;

E-mail: fboinas@fmv.utl.pt
\end{abstract}

Keywords:

bovine brucellosis; eradication programme; Portugal; test-and-slaughter; stamping-out; RB51 vaccination

\section{Summary}

Bovine brucellosis due to Brucella abortus infection causes significant reproduc-tive and production losses in cattle and is a major zoonosis. Eradication of this disease has proved difficult to achieve in Portugal where it still occurs in some regions despite an ongoing national eradication programme. In 2004, the Alent-ejo region, a major cattle producing area, reported one of the highest levels of bovine brucellosis in the country, especially in one divisional area. In that area, bovine brucellosis was particularly problematic in a holding of ten herds, the largest extensive cattle unit in the country, which remained infected despite an extensive test-and-slaughter programme and depopulation of five herds. A 5-year programme of RB51 vaccination with biannual test-and-slaughter was thus implemented in 2004. The apparent animal seroprevalence decreased from 19\% $(646 / 3,400)$ to $3 \%(88 / 2930)$ on the third herd-level test and remained below $0.8 \%(27 / 3324)$ after the fourth test. After the tenth test, the holding had a prevalence of $0.1 \%$ (2/2332) and only one herd remained positive with a within-herd prevalence of $1.1 \%(2 / 177)$. The results were compared to all other herds $(n=10)$ in the divisional area that were also persistently infected but were subject only to test-and-slaughter before being depopulated. In these herds, the strategy of test-andslaughter did not reduce the prevalence, which remained significantly higher than the vaccinated group (median $=0.48 \%$ and $8.5 \%$ in vaccinated versus non-vaccinated herds; Wilcoxon rank sum test; $P<0.01$ ). The success of this pilot programme in continental Portugal pro-vided a valuable case study to the official veterinary services by illustrating the value of RB51 vaccination with parallel testing and improved biosecurity as a comprehensive and sustainable strategy for bovine brucellosis control in persis-tently infected herds.

\section{Introduction}

Bovine brucellosis is a worldwide, zoonotic disease of cattle caused by Brucella abortus, characterized by reproductive failure in females and potential infertility in males. The main clinical signs in sexually mature cows are abortions which occur most commonly in the last trimester of gestation (Crawford et al., 1990). Large numbers of organisms are excreted during infected abortions and the highly contaminated lochia present a significant risk for transmission to cattle in the immediate vicinity (Nicoletti, 1980; Corner, 1983; Samartino and Enright, 1993). Progeny may be infected in utero or during the perinatal period and may become long-term carriers, with the risk of future abortions (Wilesmith, 1978). 
Herd-level risk factors for infection include herd density, herd size, contiguous infection, presence of abortions in herds, cattle movement and uncontrolled or open-calving systems (Kellar et al., 1976; Nicoletti, 1980; Crawford et al., 1990; Abernethy, 2008).

Bovine brucellosis has been eradicated from many member states of the European Union (EFSA, 2013), and national programmes, governed by local and European legislation, are employed where it persists. Eradication is hampered by the lack of pathognomonic symptoms, the inability of diagnostic tests to identify all infected animals, latent carriers and the limitations of vaccines to fully protect susceptible cattle (European Commission, 2009). Control methods include test-and-slaughter or stamping-out when the prevalence is low or vaccination when the prevalence is high or control resources are constrained. Vaccination alone is insufficient to eradicate the disease, but it increases resistance to infection and reduces both the risk of abortions and excretion of the organism (European Commission, 2009). Two vaccines against bovine brucellosis are commercially available: S19 or RB51. The antibodies induced by RB51 do not react in standard agglutination tests (Rose Bengal test (RBT), serum agglutination test (SAT) or complement fixation test (CFT) (Schurig et al., 1991; European Commission, 2009).

A control programme for bovine brucellosis in Portugal commenced in 1938 (Decreto-Lei 29:181) and was enhanced in the early 1970 s by vaccination with S19 or 45/ 20, combined with testing and slaughter of positive animals (DGSP, 1977; DGV, 1979). Current control measures include serological testing of all susceptible cattle, slaughter of seropositive animals, depopulation under certain circumstances, laboratory confirmation of infection, premovement testing, post-abortion reporting and vaccination (DGV, 2007; DSSPA, 2011).

Some herds can remain persistently infected and present a serious challenge for the veterinary authorities who must decide on the best sanitary strategy in addition to test-andslaughter, which could include mass vaccination or, alternatively, depopulation.

Between late 2004 and early 2009, the official veterinary services in Alentejo, a high incidence area in southern Portugal, implemented a 5-year pilot programme of RB51 vaccination with test-and-slaughter in a holding of ten extensive herds where depopulation of five of the herds had previously failed to control the disease. Up to this point, such a strategy had only been used in the Portuguese islands of the Azores where it had proved successful (Martins et al., 2009, 2010). The objective of the Alentejo study was to evaluate the results of the strategy, compared with the outcome of similar herds in the region that also experienced persistent infection but which were subject to the regular test-and-slaughter programme with stamping-out.

\section{Materials and Methods}

\section{Background}

National and regional prevalence

The national herd and animal-level prevalence in Portugal between 2000 and 2004 ranged from $0.44 \%$ to $0.67 \%$ and $0.20 \%$ to $0.30 \%$, respectively (Fig. 1a,b; DGV, 2007). In 2004, national levels of brucellosis were mainly influenced by the high prevalence in Alentejo, a Portuguese region in the south of the country, with $2.01 \%$ of herd and $0.45 \%$ of animal-level prevalence (Figs 1a,b and 2).

Alentejo is a major cattle producing area, accounting for $43.34 \%$ of the mainland cattle population, characterized by extensive beef cattle production with larger holdings and herds than the national average (60.6 ha versus 12 ha and 122.9 versus 20.5 cattle, respectively; INE, 2006). Animals are maintained on natural pastures with feed supplements only in times of hardship. Natural breeding is predominant, and there is no synchronization of births or use of artificial insemination.

In Alentejo, the DIV of Beja experienced the highest levels of bovine brucellosis in 2004, with a herd and animallevel prevalence of $2.63 \%$ and $1.16 \%$, respectively (DIV is the smaller unit for animal health purposes, for definition of strategies at the Brucellosis eradication programmes for the European Commission; mainland Portugal is divided in 24 DIVs; Fig. 1a,b). A major factor was persistent infection in a holding of ten herds with the largest number of animals in the DIV (group of vaccinated herds of our study); Fig. 2).

\section{Vaccinated herds}

The study unit was a beef-cow enterprise with calves reared and fattened on site. Females are crossed from autochthone (indigenous) Alentejana and Mertolenga breeds, and the males are pure exotic breeds, Limousin or Charolais. The holding consisted of ten separate herds with approximately 10000 cattle (Fig. 2). In 2004, the cattle density was 1.05 animals per ha with approximately 3400 reproductive stock. Natural service was used with each breeding herd having its own bull; young stock was removed from the cows after weaning and reared separately before being finished in a single unit at the holding and moved directly to slaughter. Most of the herds were separated by doublefencing (Fig. 2), and, during the pilot programme, cattle movement between herds within the holding was prohibited. The holding was persistently infected with brucellosis despite intensive testing and depopulation of five herds between September 1999 and August 2000 (Table 1; Direcção Geral de Veterinária (DGV), 2007). Restocking was permitted only after 1 year and after the pastures had been ploughed in. Despite these measures, however, the herds were re-infected within 1 year. 
(a)

Percentage of positive herds (\%)

- National …..... Alentejo region DIV Beja

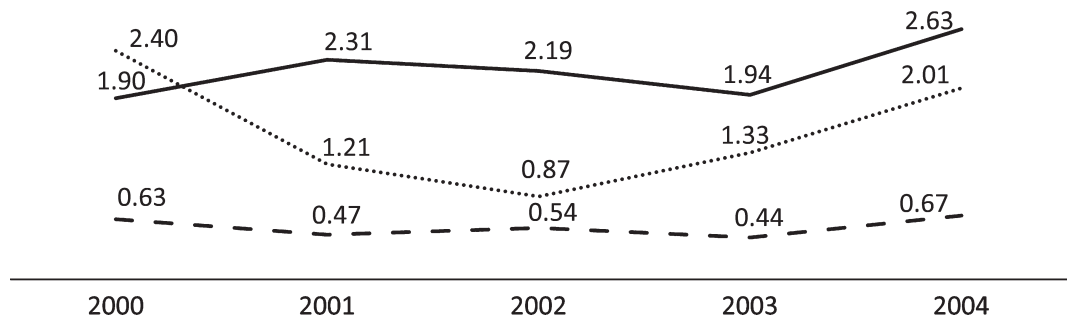

(b)

Percentage of positive animals (\%)

— National .......... Alentejo region _ DIV Beja

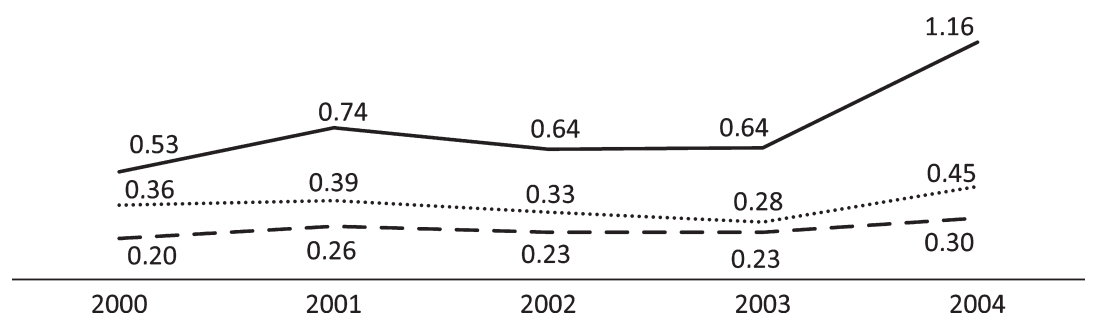

Fig. 1. (a, b) Comparison between the herd (a) and anima-level prevalence (b) for bovine brucellosis between mainland Portugal, Alentejo region and the DIV of Beja, 2000 and 2004.

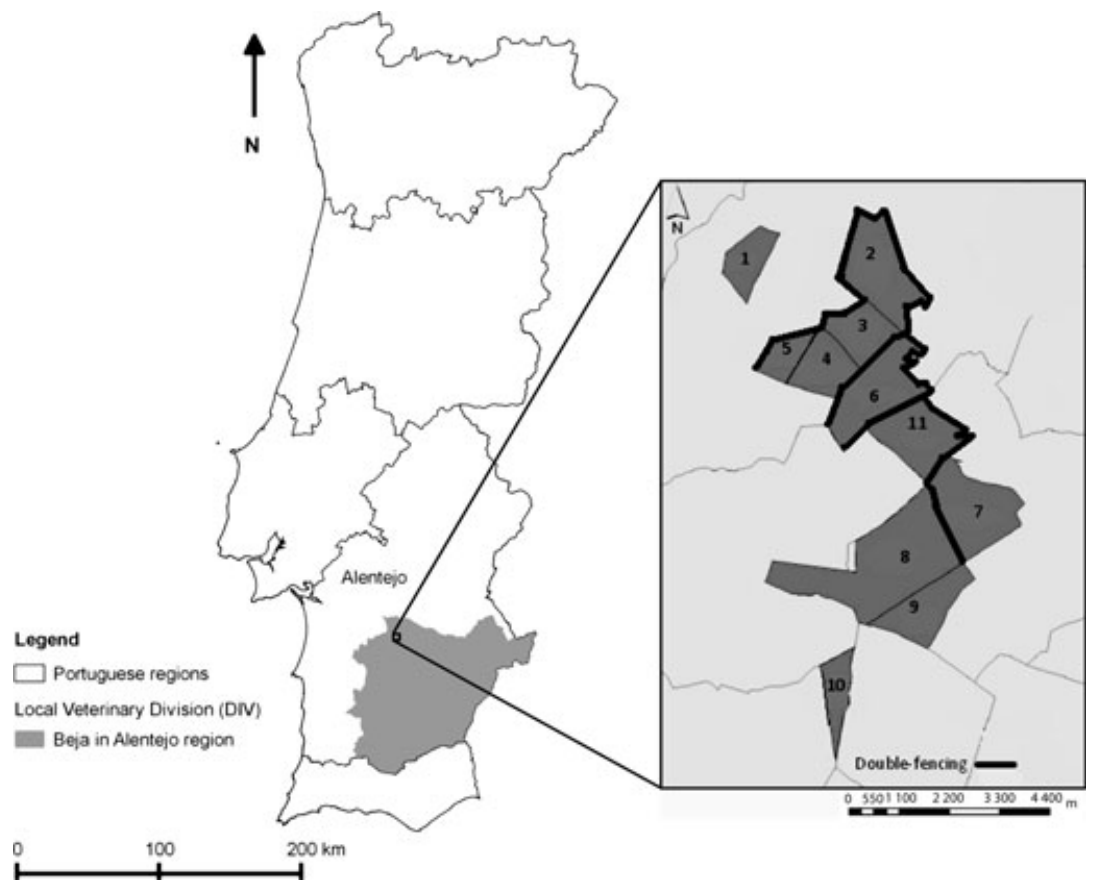

Fig. 2. Location of the ten cattle herds vaccinated with RB51 in Beja DIV, Alentejo region, Portugal.

The 10 vaccinated herds were grouped using the mean animal apparent prevalence in 2004, into two distinct groups: a high prevalence contiguous group (prev- alence $=37.3 \% ; \quad \mathrm{SE}=6.5 \%)$ and $\quad$ a low prevalence group (prevalence $=0.64 \% ; \mathrm{SE}=1.3 \%$; Table 2 ). There were ten farms neighbouring the study unit between 
Table 1. Regulatory actions, seroprevalence and birth rate in ten Brucella-infected herds in the Alentejo region of Portugal before and after initiation of RB51 vaccination in 2004

\begin{tabular}{|c|c|c|c|c|c|c|c|c|}
\hline \multirow[b]{2}{*}{ Year } & \multicolumn{5}{|c|}{ Herds } & \multicolumn{2}{|l|}{ Cattle } & \multirow[b]{2}{*}{ Birth rate (\%) } \\
\hline & Total & Positive & Depopulated & Restocking & Purchase & Vaccinated & Prev. (\%) & \\
\hline 1999 & 8 & 8 & 3 & 0 & 0 & 0 & 26.4 & NA \\
\hline 2000 & 5 & 5 & 2 & 0 & 0 & 0 & 18.1 & NA \\
\hline 2001 & 7 & 7 & 0 & 3 & 1 & 0 & 7.6 & NA \\
\hline 2002 & 9 & 9 & 0 & 2 & 0 & 0 & 4.3 & NA \\
\hline 2003 & 10 & 8 & 0 & 0 & 1 & 0 & 12.6 & NA \\
\hline $2004^{a}$ & 10 & 7 & 0 & 0 & 0 & 3370 & 19 & 60.1 \\
\hline 2005 & 10 & 6 & 0 & 0 & 0 & 846 & 5.7 & 44.3 \\
\hline 2006 & 10 & 6 & 0 & 0 & 0 & 709 & 0.5 & 66.0 \\
\hline 2007 & 10 & 3 & 0 & 0 & 0 & 755 & 0.5 & 68.6 \\
\hline 2008 & 10 & 1 & 0 & 0 & 0 & 331 & 0.2 & 71.9 \\
\hline $2009^{a}$ & 10 & 1 & 0 & 0 & 0 & 0 & 0.1 & 73.5 \\
\hline
\end{tabular}

ane semester; Prev., animal prevalence; NA, not available.

Table 2. Numbers of cattle tested and percentage of animals seropositive for brucellosis in five high and five low prevalence Brucella-infected herds in the Alentejo region of Portugal after initiation of RB51 vaccination in 2004

\begin{tabular}{|c|c|c|c|c|c|c|c|c|c|c|c|}
\hline \multirow[b]{2}{*}{ Group $^{a}$} & \multirow[b]{2}{*}{ Herd } & \multirow{2}{*}{$\begin{array}{l}2004 \\
\mathrm{~T} 1 \\
n(\%)\end{array}$} & \multicolumn{2}{|l|}{2005} & \multicolumn{2}{|l|}{2006} & \multicolumn{2}{|l|}{2007} & \multicolumn{2}{|l|}{2008} & \multirow{2}{*}{$\begin{array}{l}2009 \\
\text { T10 } \\
n(\%)\end{array}$} \\
\hline & & & $\begin{array}{l}\mathrm{T} 2 \\
n(\%)\end{array}$ & $\begin{array}{l}\text { T3 } \\
n(\%)\end{array}$ & $\begin{array}{l}\mathrm{T} 4 \\
n(\%)\end{array}$ & $\begin{array}{l}\text { T5 } \\
n(\%)\end{array}$ & $\begin{array}{l}\text { T6 } \\
n(\%)\end{array}$ & $\begin{array}{l}\mathrm{T7} \\
n(\%)\end{array}$ & $\begin{array}{l}\text { T8 } \\
n(\%)\end{array}$ & $\begin{array}{l}\text { T9 } \\
n(\%)\end{array}$ & \\
\hline 1 & 2 & $483(39.5)$ & $312(16.3)$ & 257 (1.9) & $279(0)$ & $215(0)$ & $265(0.8)$ & $280(0.4)$ & $337(0)$ & $301(0)$ & $227(0)$ \\
\hline 1 & 3 & $155(31.6)$ & $116(18.1)$ & $96(9.4)$ & $172(0)$ & $180(0)$ & $205(0.5)$ & $104(0)$ & $230(0)$ & $249(0)$ & $213(0)$ \\
\hline 1 & 4 & $174(29.3)$ & $139(7.9)$ & $125(0.8)$ & $123(0)$ & $220(0.5)$ & $187(0)$ & $200(0)$ & $205(0)$ & $222(0)$ & $140(0)$ \\
\hline 1 & 5 & $338(44.1)$ & $224(22.8)$ & $174(2.9)$ & $185(1.1)$ & 155 (3.9) & $219(2.7)$ & $222(5)$ & $292(2.1)$ & $283(2.5)$ & $177(1.1)$ \\
\hline 1 & 6 & $613(41.9)$ & $377(16.4)$ & $240(13.8)$ & $298(0.7)$ & $281(0.7)$ & $283(0)$ & $341(0.3)$ & $439(0)$ & $433(0)$ & $333(0)$ \\
\hline 2 & 1 & $236(3)$ & $250(1.6)$ & $247(1.6)$ & $249(0)$ & $237(0.8)$ & $210(0)$ & $220(0)$ & $188(0)$ & $212(0)$ & $166(0)$ \\
\hline 2 & 7 & $489(0.2)$ & $596(0)$ & $662(0)$ & $841(0)$ & $850(1.3)$ & $800(0)$ & $843(0)$ & $748(0)$ & $721(0)$ & $456(0)$ \\
\hline 2 & 8 & $119(0)$ & $208(0)$ & $186(0)$ & $212(0.5)$ & $180(0.6)$ & $228(0)$ & $209(0)$ & $190(0)$ & $197(0)$ & $140(0)$ \\
\hline 2 & 9 & $631(0)$ & $676(0)$ & $740(0)$ & $809(0)$ & $829(0.2)$ & $896(0)$ & $832(0)$ & $693(0)$ & $677(0)$ & $379(0)$ \\
\hline 2 & 10 & $162(0)$ & $155(0)$ & $203(0)$ & $225(0)$ & $177(0)$ & $208(0)$ & $212(0)$ & $159(0)$ & $155(0)$ & $101(0)$ \\
\hline Total/\% & & 3400 (19) & $3053(8.3)$ & $2930(3)$ & $3393(0.2)$ & $3324(0.8)$ & $3501(0.4)$ & $3463(0.6)$ & $3481(0.2)$ & $3450(0.20)$ & $2332(0.1)$ \\
\hline
\end{tabular}

${ }^{a} 1$ = High prevalence group; 2 = Low prevalence group.

1999 and 2003 of which four were infected with brucellosis.

Non-vaccinated herds

All herds $(n=10)$ with recurrent brucellosis between 1999 and 2009 in the DIV of Beja were included for comparative reasons (Table 3 ). These herds, with an average size of 203 ha, produced beef cattle in the typical extensive or semi-extensive production systems of Alentejo Region. The breeds and reproductive management were the same as that on the vaccinated holding. These herds were persistently infected with brucellosis for a minimum of two and up to 4 years.

\section{Eradication programme}

The pilot vaccinated programme commenced in the study herds in the second half of 2004 and included RB51 vacci- nation $\left(\mathrm{CZV}^{\circledR} \mathrm{SA}\right.$, Spain; 10-34 $\times 109 \mathrm{CFU} /$ dose; $\left.2 \mathrm{ml}\right)$ of all female cattle older than 4 months. In the high prevalence group of herds $(n=5$, Table 2$)$, most of the animals vaccinated as heifers during 2004 and the first half of 2005 were revaccinated six to twelve months later. Subsequently, only replacement heifers (4-12 months old) were vaccinated and no revaccination took place. Vaccination was not implemented in the first half of 2009 (the 10th round) as no replacement females were introduced due to management changes and a decision by the owners to reduce the reproductive stock (Table 1 ).

All vaccinated females were identified by means of an intraruminal bolus. All breeding and replacement animals were tested biannually, and replacement females were acquired exclusively from officially brucellosis-free herds, with a negative pre-movement test and RB51 vaccination followed by quarantine until serological results. All sero- 
Table 3. Follow-up of the ten Brucella-infected herds in the Alentejo region of Portugal not subject to RB51 vaccination

\begin{tabular}{|c|c|c|c|c|c|}
\hline ID herd & $\begin{array}{l}\text { 1st intervention } \\
\text { with positives }\end{array}$ & $\begin{array}{l}\text { Depopulation } \\
\text { (year) }\end{array}$ & $\begin{array}{l}\text { Repopulation } \\
\text { (year) }\end{array}$ & $\begin{array}{l}\text { Year of first seropositivity } \\
\text { after repopulation }\end{array}$ & Follow-up \\
\hline 1 & 2001 & 2003 & Yes (2004) & & Negative \\
\hline 2 & 2001 & 2003 & Yes (2004) & 2004 & Positive until 2006 and negative thereafter \\
\hline 3 & 1999 & 2003 & Yes (2004) & 2004 & Positive until 2005 and negative thereafter \\
\hline 4 & 2003 & 2004 & No & & Ceased activity \\
\hline 5 & 2001 & 2004 & Yes (2009) & & Negative \\
\hline 6 & 2004 & 2005 & No & & Ceased activity \\
\hline 7 & 2003 & 2006 & Yes (2007) & 2009 & Positive after 2009 thereafter \\
\hline 8 & 2005 & 2006 & Yes (2007) & & Negative \\
\hline 9 & 2006 & 2007 & No & & Ceased activity \\
\hline 10 & 2007 & 2008 & No & & Ceased activity \\
\hline
\end{tabular}

positive animals were sent directly to slaughter within 2 weeks of testing for unvaccinated cattle and within 4 weeks for vaccinated animals, the latter delay due to withdrawal period requirements. Epidemiological investigations were conducted in seropositive herds, and samples were taken for bacteriological culture from seropositive animals until confirmation of active infection. Only $\mathrm{Bru}$ cella abortus biovar 3 was isolated by the National Reference Laboratory (LNIV, Lisbon).

The comparative herds were subject to the National Eradication Programme that included test-and-slaughter of positive animals, laboratory isolation of Brucella abortus biovar 3, movement restrictions of positive herds, epidemiological investigations and repeated short-interval testing until the herds achieved freedom of infection. However, they were eventually depopulated due to ongoing, persistent evidence of infection.

\section{Serological tests}

The serological procedure was the same for both the vaccinated and non-vaccinated herds with all cattle over 6 months in each herd being tested twice a year. The RBT and CFT were used for testing and applied according to European Commission requirements (European Commission, 2009). Up to the end of 2004, animals were screened with RBT and confirmed by CFT; those positive to both tests were considered to be infected and were slaughtered. From 2005 onwards, all samples from the vaccinated herds were interpreted in parallel, and cattle positive to either test were considered positive if there was at least one CFT-positive animal in the herd. Pre-movement testing included both RBT and CFT, also interpreted in parallel. Positive animals were separated from the rest of herd and slaughtered. Bacteriological isolation was used to confirm the infected status of new positive herds. Samples were taken from serological reactors until the organism was isolated and the herd was confirmed as infected. Cultures were performed on Farrell's medium, according to the procedures described by Alton et al. (1988), on stomach contents, lung and spleen of aborted foetuses, or on retropharyngeal and supramammary lymph nodes and spleen. Brucella strains isolated were biotyped by the National Reference Laboratory (LNIV, Lisbon).

\section{Data sources and statistical analysis}

Data regarding the historical activity of the herds and control measures applied between 1999 and 2009 were obtained from PISA, the Official Animal Health Software, which is a national information system regarding sanitary activities under the official eradication programmes of ruminant diseases. For the vaccinated group, birth rate data were obtained from SNIRA, the National Information and Registration System. Microsoft Access ${ }^{\circledR}$ and Excel $^{\circledR}$ were used for data storage and management. Statistical analysis was undertaken in $\mathrm{R}$ version 2.13.1 ( $\mathrm{R}$ Core Team, 2012), and effects were considered significant if $P<0.05$; all $P$ values were two sided. The number of animals seropositive and tested in the herd was used to determine animal prevalence, both in the vaccinated and non-vaccinated groups. Birth rate was calculated as the total number of births with respect to the total number of adult females present in each herd. Mapping was developed in Quantum GIS version 2.0.1 (http://www.qgis.org/ en/site/).

In the vaccinated herds, differences in the median animal-level prevalence between high and low prevalence herd group was tested with Wilcoxon rank sum test. Analysis of Variance (ANOVA), followed by post hoc Tukey's HSD, was used to assess the evolution of the birth rate in the holding between 2004 and 2009. The correlation between birth rate and herd prevalence was assessed using Spearman's correlation coefficient. Differences in the median animal-level prevalence over the period between the group of vaccinated and non-vaccinated herds were tested using Wilcoxon rank sum test. 


\section{Results}

The vaccinated group comprised ten herds but, between 1999 and 2002, the number varied between five and nine due to depopulation associated with high within-herd prevalence. From 2003-2009, the number present increased to ten (Table 1) with only one herd (herd 5) having seropositive animals in the last 2 years of the study $(2008,2009)$. The animal-level prevalence in this herd was $2.3 \%$ (thirteen positive animals) in 2008, reducing to $1.1 \%$ (two positive animals) by the first round of testing in 2009 (Table 2). The mean animal-level prevalence in the holding decreased from $19 \%$ in $2004(\mathrm{SE}=6.3)$ to $0.1 \%$ in $2009(\mathrm{SE}=0.1)$ (Table 2; Fig. 3a). In the herd high prevalence group (Group 1, Table 2), the mean animal-level prevalence reduced from $37.3 \%$ in $2004-16.3 \%$ by the first half of 2005 and to $5.8 \%$ by the second half of that year. The prevalence in herd Group 1 was significantly higher than in herd Group 2 in 2004 and 2005 (Wilcoxon rank sum test; $P<0.05$ ), but not from 2006 onwards. In the low prevalence group, two herds that were initially negative (Herds 8 and 9) were seropositive in at least one round of the serological survey in 2006, becoming negative thereafter. The same occurred in 2007 in Herds 2 and 3 of the high preva-
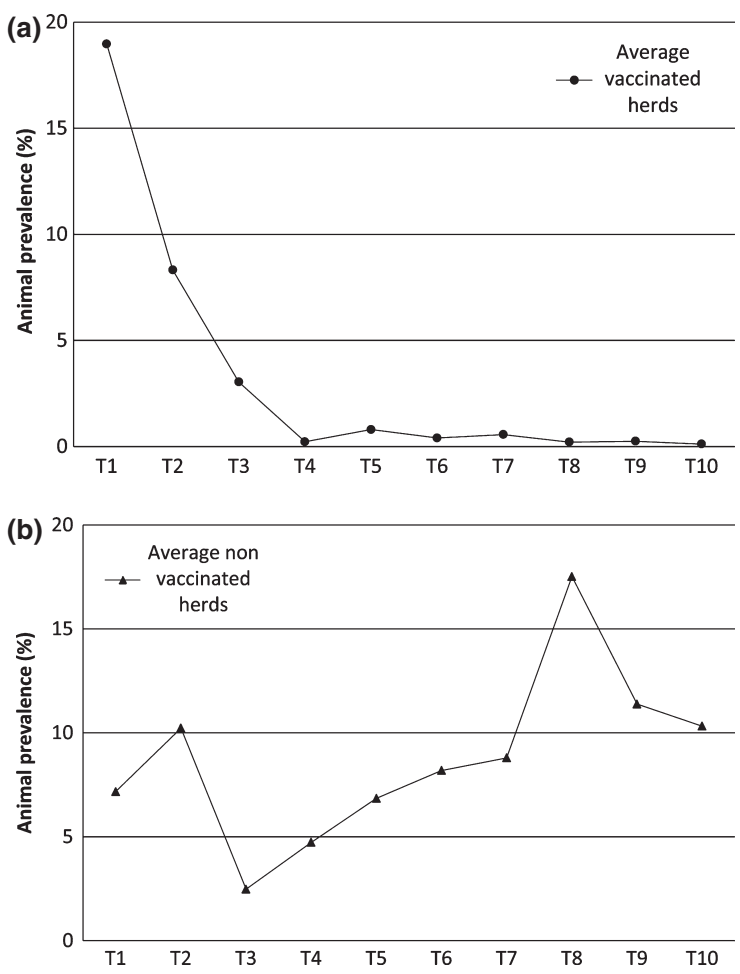

Fig. 3. (a) Seroprevalence of brucellosis in 10 vaccinated infected cattle herds in the Alentejo region of Portugal (1999-2009). (b) Seroprevalence of brucellosis in 10 non-vaccinated infected cattle herds in the Alentejo region of Portugal (1999-2009). lence group, with, respectively, two and one seropositive animals; the herds tested negative thereafter.

Between 2004 and 2005, the birth rate decreased and this was associated with removal of 646 cattle at the start of the vaccinated programme, but increased annually thereafter (to $73.5 \%$ by 2009 ; Table 1) (one-way Anova followed by post hoc Tukey's HSD; $F=7.72 ; P<0.001)$. This increase in the birth rate over the 5 -year period was negatively correlated with the reduction in animal-level prevalence in the same period (Spearman's correlation coefficient (rho) $=-0.93 ; P=0.008)$. No reports of abortion associated with RB51 vaccination were reported during the study period.

In the ten non-vaccinated herds, the median number of herd-level serological tests was 6 (range: $1-10$ ) with a median between-test interval of 84 days. The mean animal-level prevalence at the first test was 7.2\% $(\mathrm{SE}=3.6)$ and the prevalence increased across the observed period except for the third test (mean animal-level prevalence $=2.5 \%$; $\mathrm{SE}=1.2$; Fig. $3 \mathrm{~b}$ ). The median animal-level prevalence over the period in the non-vaccinated herds was significantly higher than the vaccinated group $(8.5 \%$ versus $0.48 \%$; Wilcoxon rank sum test; $P<0.01$ ).

Four of the non-vaccinated herds ceased production activity after depopulation (Herds 4, 6, 9 and 10, Table 3); three remained negative after depopulation and repopulation (Herds 1, 5 and 8) and two herds became positive temporarily and negative $1 / 2$ years later (Herds 2 and 3 ). Herd 7 tested negative after the repopulation, but was seropositive 2 years later (Table 3 ).

\section{Discussion}

Bovine brucellosis infection leads to severe financial losses in affected herds due to abortions, slaughter of test-positive animals and restriction of animal movements and trade. Successful eradication programmes are therefore costly to both the farming industry and government and difficult to implement as they usually require intensive, long-term interventions. In developed countries, strategies for eradication are based on test-and-slaughter programmes and in the early stages of a programme, vaccination to avoid bacterial dissemination (Godfroid et al., 2011).

Herds may be persistently infected with brucellosis due to ongoing exposure to external sources or from animals that had not yet seroconverted. Such herds present a serious challenge to eradication programme managers, especially from latent carriers that occur regardless of the tests used and present a risk to within-herd spread and transmission to contact herds. According to the bovine brucellosis eradication programme of Portugal, mass vaccination with RB51 or depopulation in such persistently infected herds can be applied. In our study, the strategy of test-and- 
slaughter alone was not effective in either the non-vaccinated or vaccinated groups of herds. In the ten non-vaccinated herds, it did not reduce the prevalence of brucellosis; the herds remained infected for 2-4 years and were subsequently depopulated. Four of the herds ceased activity, and in three herds, bovine brucellosis re-emerged after repopulation. Thus, bovine brucellosis can seriously disrupt production as it was associated with a high rate of abandonment of activity and herd re-infection.

The study unit comprised ten persistently infected herds, with well-known risk factors such as large herd size, contiguous infection and uncontrolled or open-calving systems (Kellar et al., 1976; Nicoletti, 1980; Crawford et al., 1990; Abernethy, 2008) and an extensive management system that made containment of the outbreaks extremely difficult (Sanz et al., 2010). Prior to the vaccination programme, there was significant within-herd spread in most of the herds and infection persisted, despite depopulation of five. Various factors may have contributed to the recurrence, such as within-herd spread due to inadequate biosecurity and ongoing infection in the neighbouring herds, but the most significant was likely failure to manage the enterprise as a single epidemiological unit at the time of depopulation. Total depopulation of the unit was rejected on economic grounds, and the herds were removed over a period exceeding 1 year, which meant restocking was similarly staggered. Thus, it is possible that restocked, Brucella-free herds would have been adjacent to infected animals where, despite double-fencing, indirect transmission was still possible. Equipment was shared between herds at certain times (for example, management of parturition, transport of feed), employees might have moved between herds, and one cannot discount the role of scavenging animals such as carrion birds or stray dogs that were present in the area. Between 1999 and 2003, four of the ten neighbouring herds outside the enterprise were also infected with bovine brucellosis, two of which were contiguous to Herds 2 and 3 (one was depopulated in 2003 and one ceased production activity). After the epidemiological investigation by the Official Veterinary Services in the infected neighbouring holdings, it was concluded that the origin of infection was the study unit before the implementation of vaccination.

The vaccination programme was implemented in the unit due to difficulties in bringing about effective management changes, the proximity of infected neighbouring holdings and the ineffectiveness of the previous depopulation. The 5-year programme (2004-2009) reported here became the standard protocol used in Portugal in situations where depopulation fails or, for sanitary reasons, depopulation is not the most appropriate or effective measure. The measures applied included multiannual testing, parallel testing to detect and eliminate infected cattle as early as possible, rapid slaughter (within 2 or 4 weeks) of all posi- tive animals and vaccination with RB51. However, the frequency of four to five tests per year, as stipulated in the national programme (DGV, 2007), was replaced by biannual testing, due to the size of the unit and the limited staff resources available. Nevertheless, within 3 years of commencement, brucellosis was eliminated from seven of the ten herds and was likely eliminated from nine by the end of the 5-year programme. Brucella abortus was confirmed by bacteriological culture early in the programme, but not towards the end so one cannot be certain of the infected status of the seropositive animals at the end.

Approved diagnostic tests within the European Union include the serum agglutination test (SAT), complement fixation test (CFT), rose bengal test (RBT), enzyme-linked immunosorbent assays (ELISA), the brucellin skin test (BST), the milk ring test (MRT) and the fluorescence polarization assay (Directive 64/432/CEE). Despite this wide range, none has optimal sensitivity or specificity, requiring different test strategies based on the stage of eradication and objective of the test strategy (Abernethy et al., 2012). The diagnostic tests most frequently used are the RBT, suitable for screening herds and individual animals, and the CFT which is used for both screening and confirmation (OIE, 2009; Sanz et al., 2010).

Parallel testing improves sensitivity and is specially valuable when early detection is desirable (Houe et al., 2004; Abernethy et al., 2012), but it reduces specificity (Houe et al., 2004); thus, it is likely that some of the later incidents of few reactors and no subsequent seropositivity in the herds were likely false positives as, for example, the sporadic positives in the low prevalence group in 2006.

No bacterial isolation was performed towards the end of the period as culture was only undertaken until infection was confirmed. It is not possible therefore to determine the true status of the singleton, seropositive animals identified towards the end. These may have been false positives, a common feature in brucellosis surveillance, or truly infected animals, illustrating the need for long-term interventions in such herds.

RB51 is an attenuated rough strain vaccine which gives no false positives post-vaccination when using conventional serological tests, thus no interference with epidemiological surveillance (Stevens et al., 1995; Herrera-López et al., 2010). RB51 vaccination was undertaken in all female cattle, including young, adult and pregnant animals, achieving rapid protection of the herd. S19 vaccine has been successfully used to eradicate bovine brucellosis for over 50 years (Godfroid et al., 2011). Despite its effectiveness, it is known to induce abortion if administered to pregnant animals (Godfroid et al., 2011) and due to the antigens (polysaccharide O-side of the cell surface smooth lipopolysaccharide (LPS)) shared by both vaccine and field strains, it creates persistent titres that confound identification of 
infected cattle by most diagnostic tests, especially when adult cattle are vaccinated. Its use is therefore generally limited to young heifers of four to eight months of age (Olsen et al., 1996; Moriyon et al., 2004; Olsen and Tatum, 2010; Sanz et al., 2010). If only young calves could be vaccinated and considering an average of $20 \%$ of replacement/rate/ year, it would be necessary 5 years for full coverage of the herd.

Abortions associated with RB51 vaccination have been described (Yazdi et al., 2009). No abortions were reported during the study period, which is surprising given the size of the unit and the initial high prevalence. This may reflect difficulties in identifying aborted cows under an extensive system, with limited numbers of personnel. However, other studies also reported the low risk of abortions associated with the vaccine (Schurig et al., 1991; Uzal et al., 2000; Poester et al., 2006; Sanz et al., 2010). This was not evaluated in this study, but the marked increase in the birth rate suggests that it was not significant if it did occur. The protective effectiveness of RB51 remains controversial (Moriyon et al., 2004). It confers an adequate degree of protection against experimental infection (Poester et al., 2006) and has been used with success in some parts of the European Union (European Commission, 2009). Even though there are few reported studies, some field reports describe good results when vaccination is associated with sanitary measures (Herrera et al., 2008; Martins et al., 2009, 2010; Herrera-López et al., 2010; Sanz et al., 2010).

This study demonstrated the value of RB51 whole-herd vaccination, in combination with test-and-slaughter and biosecurity measures in controlling bovine brucellosis. The within-herd prevalence in the study herds reduced significantly after the first intervention and was effectively controlled before the tenth intervention (5 years). By contrast, the non-vaccinated herds remained infected throughout the study period and with a high prevalence. As such therefore, the vaccination approach provides a viable alternative to depopulation, especially when the risk of re-infection exists, and serves as a possible model for other regions.

This study was limited due to the observational nature of the project that used retrospective data in comparing the vaccinated and non-vaccinated groups. Although both were similar in regard to breed of cattle, management and biosecurity, they were different in that the vaccinated herds were located on a single unit in contrast to the more detached vaccinated herds. A case-control design was therefore avoided as it was not possible to evaluate the effect of this from the available data. Instead, only the within-herd prevalence was utilized as a measure of success of the contrasting interventions. It is worth noting, however, that the factors specific to the vaccinated group - increased contact, larger overall size and greater movement between herds were more likely to exacerbate persistence of infection than be protective. In other words, the rapid and progressive reduction in prevalence could reasonably attributed to the intervention than to factors common to the vaccinated herds.

This case study showed that RB51 whole-herd vaccination, in combination with test-and-slaughter and strong biosecurity measures can control the spread of the disease in a short period of time. As such therefore, it provides a viable alternative to depopulation, especially when the risk of re-infection exists. This pioneer case study in continental Portugal provided valuable support to the veterinary services as an example to other vaccination programmes.

\section{Acknowledgements}

Dr Bruno Garin Bastujii for his scientific support, Dr Ema Vale, Dr Luis Filipe Sobral, Eng ${ }^{\mathrm{a}}$ Marta Flores and $\mathrm{Mr}$ Lampreia for their valuable contribution in validating the data.

\section{Conflict of Interest Statement}

The authors declare that no conflicting financial or personal interests exist.

\section{References}

Abernethy, D. A., 2008: The epidemiology and management of bovine brucellosis in Northern Ireland. PhD thesis, The Royal Veterinary College, University of London, London, 204.

Abernethy, D. A., F. D. Menzies, S. J. McCullough, S. W. J. McDowell, K. E. Burns, R. Watt, A. W. Gordon, M. Greiner, and D. U. Pfeiffer, 2012: Field trial of six serological tests for bovine brucellosis. Vet. J. 191, 364-370.

Alton, G. G., L. M. Jones, R. D. Angus, and J. M. Verger, 1988: Techniques for the Brucellosis Laboratory. Inra, Paris, France $190 \mathrm{p}$.

Corner, L. A., 1983: Three aspects of bovine brucellosis: epidemiology, the role of bulls and vaccines. New South Wales Vet. Proc. 19, 47-48.

Crawford, R. P., J. D. Huber, and B. S. Adams, 1990: Epidemiology and surveillance. In: Nielsen, K. and J. R. Duncan (eds), Animal Brucellosis, pp. 131-151. CRC Press, Boca Raton.

Direcção de Serviços de Saúde e Protecção Animal (DSSPA), 2011: Programa de Erradicação da Brucelose dos Bovinos para o ano 2012. Direcção Geral de Veterinária, Ministério da Agricultura, Mar, Ambiente e Ordenamento do Território. Lisboa, Portugal, pp. 1-31.

Direç̧ão Geral de Veterinária (DGV), 1979: Relatório: $1^{\text {a }}$ Reunião O.M.S. para o programa de luta contra as zoonoses e doenças transmissíveis pelos alimentos nos países da Bacia do Mediterrâneo. $2^{\mathrm{a}}$ Reunião do grupo coordenador para o programa de luta contra as zoonoses na Bacia do Mediterrâneo. Pendik, Istambul. 
Direcção Geral de Veterinária (DGV), 2007: Programa de Erradicação da Brucelose dos Bovinos. Ministério da Agricultura, do Desenvolvimento Rural e das Pescas. Lisboa, Portugal, pp. $1-165$.

Direcção Geral dos Serviços Pecuários (DGSP), 1977: Acordo de sanidade veterinária Luso-Espanhol. XX Reunião das Autoridades Veterinárias. Madrid, Espanha, pp. 17-18.

Directiva do Conselho (64/432/CEE), 1964: Problemas de fiscalização sanitária em matéria de comércio intracomunitário de animais das espécies bovina e suína. JO L 121 de 29.7.1964, pp. 1977.

European Commission, 2009: Working document on eradication of bovine, sheep and goats Brucellosis in the European Union, accepted by the "Bovine" and "Sheep and Goats" Brucellosis subgroups of the Task Force on monitoring animal disease eradication. SANCO/6095/2009.

European Food Safety Authority (EFSA), 2013: The European Union Summary Report on Trends and Sources of Zoonoses, Zoonotic Agents and Food-borne Outbreaks in 2011. EFSA J. 11:3129, 250 pp.

Godfroid, J., H. C. Scholz, T. Barbier, C. Nicolas, P. Wattiau, D. Fretin, A. M. Whatmore, A. Cloeckaert, J. M. Blasco, I. Moriyon, C. Saegerman, J. B. Muma, A. L. Dahouk, H. Neubauer, and J. J. Letesson, 2011: Brucellosis at the animal/ecosystem/ human interface at the beginning of the 21st century. Prev. Vet. Med. 102, 118-131.

Herrera, E., G. Palomares, and E. Díaz-Aparicio, 2008: Milk production increase in a dairy farm under a six-year brucellosis control program. Ann. N. Y. Acad. Sci. 1149, 296-299.

Herrera-López, E., F. Suárez-Guemes, L. Hernández-Andrade, D. Córdova-López, and E. Díaz-Aparicio, 2010: Epidemiological study of Brucellosis in cattle, immunized with Brucella abortus RB51 vaccine in endemic zones. Vaccine 28S, F59-F63.

Houe, H., A. K. Ersboll, and N. Toft (eds.) (2004): Introduction to Veterinary Epidemiology. 1st edn. Multiple testing: Chapter 9.6. Biofolia. pp. 147-148. Narayana Press, Gylling, Denmark.

Instituto Nacional de Estatística (INE), 2006: Inquérito à estrutura das explorações agrícolas, 2005. Lisboa, Portugal, pp. 101.

Kellar, J., R. Marra, and W. Martin, 1976: Brucellosis in Ontario: a case control study. Can. J. Comp. Med. 40, 119-128.

Martins, H., B. Garin-Bastuji, F. Lima, L. Flor, A. P. Fonseca, and F. Boinas, 2009: Eradication of bovine brucellosis in the Azores, Portugal - Outcome of 5-years programme (20022007) based on test-and-slaughter and RB51 vaccination. Prev. Vet. Med. 90, 80-89.

Martins, H., B. Garin-Bastuji, F. Lima, L. Flor, A. P. Fonseca, and F. Boinas, 2010: Response to Letter to the Editor by Blasco and Moriyon (2009) concerning the manuscript "Eradication of bovine brucellosis in the Azores, Portugal - Outcome of 5-years programme (2002-2007) based on test-and-slaughter and RB51 vaccination”. Prev. Vet. Med. 94, 158-162.
Moriyon, I., M. J. Grillo, D. Monreal, D. Gonzalez, C. Marin, I. Lopez-Goni, R. C. Mainar-Jaime, E. Moreno, and J. M. Blasco, 2004: Rough vaccines in animal brucellosis: structural and genetic basis and present status. Vet. Res. 35, 1-38.

Nicoletti, P., 1980: The Epidemiology of Bovine Brucellosis. Adv. Vet. Sci. Comp. Med. 24, 69-98.

OIE (World Organization for Animal Health), 2009: Bovine Brucellosis. Manual of Diagnostic Tests and Vaccines for Terrestrial Animals (Chapter 2.4.3). Paris, France, pp. 1-35.

Olsen, S., and F. Tatum, 2010: Bovine Brucellosis. Vet. Clin. North. Am. Food Anim. Pract. 26, 15-27.

Olsen, S. C., D. Evans, S. G. Hennager, N. F. Cheville, and M. G. Stevens, 1996: Serologic responses of Brucella abortus strain 19 calfhood-vaccinated cattle following adult vaccination with strain RB51. J. Vet. Diagn. Invest. 8, 451-454.

Poester, F. P., V. S. P. Gonçalves, T. A. Paixão, R. L. Santos, S. Olsen, G. Schurig, and A. P. Lage, 2006: Efficacy of strain RB51 vaccine in heifers against experimental brucellosis. Vaccine 24, 5327-5334.

R Core Team, 2012: R: A Language and Environment for Statistical Computing. R Foundation for Statistical Computing, Vienna, Austria. Available at http://www.r-project.org/ (accessed January 27, 2014).

Samartino, L. E., and F. M. Enright, 1993: Pathogenesis of abortion of bovine brucellosis. Comp. Immunol. Microbiol. Infect. Dis. 16, 95-101.

Sanz, C., J. L. Sáez, J. Álvarez, M. Cortés, G. Pereira, A. Reyes, F. Rubio, J. Martín, N. García, L. Domínguez, M. Hermoso-deMendoza, and J. Hermoso-de-Mendoza, 2010: Mass vaccination as a complementary tool in the control of a severe outbreak of bovine brucellosis due to Brucella abortus in Extremadura, Spain. Prev. Vet. Med. 97, 119-125.

Schurig, G. G., R. M. Roop, T. Bagchi, S. Boyle, D. Buhrman, and N. Sriranganathan, 1991: Biological properties of RB51: a stable rough strain of Brucella abortus. Vet. Microbiol. 28, 171188.

Stevens, M. G., S. C. Olsen, and N. F. Cheville, 1995: Comparative analysis of immune responses in cattle vaccinated with Brucella abortus strain 19 or strain RB51. Vet. Immunol. Immunopathol. 44, 223-235.

Uzal, F. A., L. Samartino, G. Schurig, A. Carrasco, K. Nielsen, R. F. Cabrera, and H. R. Taddeo, 2000: Effect of vaccination with Brucella abortus strain RB51 on heifers and pregnant cattle. Vet. Res. Commun. 24, 143-151.

Wilesmith, J. W., 1978: The persistence of Brucella abortus infection in calves: a retrospective study of heavily infected herds. Vet. Rec. 103, 149-153.

Decreto-Lei n 29:181 de 24 de Novembro, 1938: Ministério da Agricultura, Lisboa, Portugal, pp. 1541.

Yazdi, H. S., M. Kafi, M. Haghkhah, A. Tamadon, A. M. Behroozikhah, and M. Ghane, 2009: Abortions in pregnant dairy cows after vaccination with Brucella abortus strain RB51. Vet. Rec. 165, 570-571. 